Article

\title{
Evaluation of Four Indigenous Non-Saccharomyces Yeasts Isolated from the Shangri-La Wine Region (China) for Their Fermentation Performances and Aroma Compositions in Synthetic Grape Juice Fermentation
}

\author{
Yue Zhao ${ }^{1,2} \mathbb{D}^{\text {, Qingyang Sun }}{ }^{1} \mathbb{D}$, Bin Tian ${ }^{3} \mathbb{D}$, Shusheng Zhu ${ }^{1}$, Fei Du ${ }^{1}$, Ruzhi Mao ${ }^{4,5}$, Su Li $^{6}$, Lijing Liu $^{4,5}$ \\ and Yifan Zhu $1,4,5, *$
}

Citation: Zhao, Y.; Sun, Q.; Tian, B.; Zhu, S.; Du, F.; Mao, R.; Li, S.; Liu, L.; Zhu, Y. Evaluation of Four Indigenous Non-Saccharomyces Yeasts Isolated from the Shangri-La Wine Region (China) for Their

Fermentation Performances and Aroma Compositions in Synthetic Grape Juice Fermentation. J. Fungi 2022, 8, 146. https://doi.org/ $10.3390 /$ jof 8020146

Academic Editor: Martin Zarnkow

Received: 4 January 2022

Accepted: 27 January 2022

Published: 30 January 2022

Publisher's Note: MDPI stays neutral with regard to jurisdictional claims in published maps and institutional affiliations.

Copyright: (c) 2022 by the authors. Licensee MDPI, Basel, Switzerland. This article is an open access article distributed under the terms and conditions of the Creative Commons Attribution (CC BY) license (https:// creativecommons.org/licenses/by/ $4.0 /)$.
1 College of Plant Protection, Yunnan Agricultural University, Kunming 650201, China; zhaoyue_0335@126.com (Y.Z.); sunqingyang0913@163.com (Q.S.); shushengzhu79@126.com (S.Z.); dufeifei2018@163.com (F.D.)

2 College of Food Science, Hebei Normal University of Science \& Technology, Qinhuangdao 066600, China

3 Faculty of Agriculture and Life Sciences, Lincoln University, Lincoln 7647, New Zealand; bin.tian@lincoln.ac.nz

4 College of Food Science and Technology, Yunnan Agricultural University, Kunming 650201, China; 18082970271@163.com (R.M.); cherry.liu@vip.163.com (L.L.)

5 University Engineering Research Center for Grape \& Wine of Yunan Province, Yunnan Agricultural University, Kunming 650201, China

6 College of Horticulture and Landscape, Yunnan Agricultural University, Kunming 650201, China; evillife_t@hotmail.com

* Correspondence: yifanzhuyy@163.com

\begin{abstract}
This study investigated the fermentation performances and aroma compositions of synthetic grape juice that was fermented by four indigenous non-Saccharomyces yeast isolates that were obtained from the Shangri-La wine region (China): Meyerozyma guilliermondii (AD-58), Saccharomycopsis vini (BZL-28), Saturnispora diversa (BZL-11), and Wickerhamomyces anomalus (DR-110), in comparison to those of Saccharomyces cerevisiae (EC1118). The four indigenous non-Saccharomyces yeasts showed a lower fermentative capacity and a lower conversion rate of sugar to alcohol, but a higher yield of volatile acidity. W. anomalus (DR-110) had a greater ability to produce numerous esters and short-chain fatty acids and the representative flavors of its fermented medium were fruity and fatty. Sac. vini (BZL-28), interestingly, exhibited great capacity in the formation of many monoterpenes, particularly (Z)- $\beta$-ocimene, $E$ - $\beta$-ocimene, linalool, citral, and geraniol and its fermented medium was characterized by a strong fruity (citrus-like) and floral flavor. M. guilliermondii (AD-58) and Sat. diversa (BZL-11) only mildly affected the aroma profiles of their resultant fermented media, since the concentrations of most of the volatiles that were produced by these two isolates were much lower than their sensory thresholds. The four indigenous non-Saccharomyces yeasts exhibited distinctive fermentation performances and aroma production behaviors. In particularly, W. anomalus (DR-110) and Sac. vini (BZL-28) have shown good potential in enhancing the aromas and complexity of wine.
\end{abstract}

Keywords: pure culture fermentation; Meyerozyma guilliermondii; Saccharomycopsis vini; Saturnispora diversa; Wickerhamomyces anomalus

\section{Introduction}

Wine fermentation is a complex biochemical process that is conducted by many different microorganisms. Saccharomyces and non-Saccharomyces yeasts are the predominant microorganisms that are responsible for wine's fermentation [1]. In the past, non-Saccharomyces yeasts were usually isolated from sour wine and associated with unpleasant flavor, therefore oenologists tend to inhibit the activity of these yeasts during wine fermentation [2]. 
By contrast, S. cerevisiae yeasts are more favored in wine production for their reliable fermentation characteristics with consistent quality [2].

Recent studies have revealed the new roles of non-Saccharomyces yeasts in wine production, particularly for some specific enological characteristics. For example, Hanseniaspora, Metschnikowia, Starmerella, and Zygosaccharomyces have shown a lower sugar-ethanol conversion rate during fermentation, thus they could be applied to produce a reducedalcohol wine [3,4]. Furthermore, some non-Saccharomyces yeasts like Lachancea thermotolerans, Pichia kudriavzevii, and Schizosaccharomyces pombe have shown potential in regulating acidity during wine fermentation, which could be used for improving the quality of must containing excessive or insufficient acidity [5-7]. Several strains of Aureobasidium pullulans, Cystofilobasidium capitatum, Cryptococcus saitoi, Rhodosporidiobolus colostri, and Rhodotorula dairenensis have shown great capability of improving the color quality of wines by producing pectinase during fermentation [8].

The aroma is one of the most important sensory properties of wine and the influence of non-Saccharomyces yeasts on the wine's aroma has always been the main focus of wine research. Compared with S. cerevisiae, some non-Saccharomyces yeasts, such as Metschnikowia pulcherrima, Pichia kudriavzevii, Torulaspora delbrueckii, Lachancea thermotolerans, and Zygosaccharomyces bailii have exhibited unique behaviors in producing volatile aroma compounds [6,9]. Consequently, the application of non-Saccharomyces yeasts in the production of wine or other beverages could have a great contribution to their aromatic complexity [7,10-13]. In addition, most of the non-Saccharomyces yeasts are good producers of highly active glycosidase (typically $\beta$-D-glucosidase) [14,15]. These enzymes could release varietal aromas, such as terpenols, terpene diols, and $\mathrm{C}_{13}$-norisoprenoids from the corresponding precursors that existed in the grape must [16]. This feature of the non-Saccharomyces yeasts has also been employed by some researchers in order to enhance the primary aroma of wine $[17,18]$.

Diverse non-Saccharomyces yeasts are widely distribute in the vineyards and on the surface of grapes $[19,20]$. Although some of them have been confirmed to exhibit unique performances during fermentation, there are still many undiscovered oenological behaviors of non-Saccharomyces yeasts that deserve to be explored. Shangri-La is a distinctive Chinese wine region that has the highest altitude vineyards and is rich in biodiversity. In our previous work, a number of non-Saccharomyces yeast isolates have been found in this region [21], but most of them have not been studied for their potential application in wine production.

Therefore, the aim of the present study was to explore the oenological behaviors of four indigenous non-Saccharomyces yeast isolates that were obtained from the Shangri-La wine region (China), including Meyerozyma guilliermondii (AD-58), Saccharomycopsis vini (BZL-28), Saturnispora diversa (BZL-11), and Wickerhamomyces anomalus (DR-110). To this end, the fermentation performances of these four isolates in synthetic grape juice have been studied and compared to a commercial Saccharomyces cerevisiae yeast (EC1118). The aroma compositions in the resultant fermented media have also been analyzed for their potential contribution to aroma enhancement and regional characteristics.

\section{Materials and Methods}

\subsection{Microorganisms}

The four non-Saccharomyces yeast isolates, Meyerozyma guilliermondii (M. guilliermondii, AD-58), Saccharomycopsis vini (Sac. vini, BZL-28), Saturnispora diversa (Sat. diversa, BZL-11), and Wickerhamomyces anomalus (W. anomalus, DR-110), were obtained from the spontaneous fermentation of Cabernet Sauvignon wines in the Shangri-La wine region, Yunnan, China [21]. A commercial Saccharomyces cerevisiae yeast (S. cerevisiae, EC1118) (Lallemand Inc., Montreal, QC, Canada) was used for comparison. The colony morphologies, on YPD and WL agar, of these non-Saccharomyces yeast isolates have been presented in Figure S1. The detailed information of the 26S rRNA D1/D2 region and the 5.8S rRNA ITS region of these non-Saccharomyces yeast isolates are listed in Table S1. The phylogenetic trees of 
the four non-Saccharomyces yeast isolates, based on the sequence analyses of the $26 \mathrm{~S}$ rRNA D1/D2 region and 5.8S rRNA ITS region, have been presented in Figures S2 and S3.

\subsection{Fermentations in Synthetic Grape Juice}

Fermentation was carried out in triplicate in $500 \mathrm{~mL}$ Erlenmeyer flasks containing $300 \mathrm{~mL}$ of synthetic grape juice (SGJ). The SGJ was prepared according to the manufacturer's instructions (Shandong Tuopu Biol-engineering Co., Ltd., Zhaoyuan, Shandong, China) and sterilized by filtration $(0.22 \mu \mathrm{m}$ sterile membrane). The detailed compositions of the SGJ (1 L) are as follows: $90 \mathrm{~g}$ D-glucose, $90 \mathrm{~g}$ D-fructose, $3 \mathrm{~g}$ L-tartaric acid, $0.3 \mathrm{~g} \mathrm{~L}$-malic acid, $0.3 \mathrm{~g}$ citric acid, $2.0 \mathrm{~g} \mathrm{KH}_{2} \mathrm{PO}_{4}, 0.2 \mathrm{~g} \mathrm{MgSO}_{4} \cdot 7 \mathrm{H}_{2} \mathrm{O}, 0.3 \mathrm{~g}\left(\mathrm{NH}_{4}\right)_{2} \mathrm{SO}_{4}, 0.6 \mathrm{~g}$ Asparagine, $4 \mathrm{mg} \mathrm{MnSO}_{4} \cdot \mathrm{H}_{2} \mathrm{O}, 4 \mathrm{mg} \mathrm{ZnSO} \cdot 7 \mathrm{H}_{2} \mathrm{O}, 1 \mathrm{mg} \mathrm{CuSO} \cdot 5 \mathrm{H}_{2} \mathrm{O}, 1 \mathrm{mg} \mathrm{KI}, 1 \mathrm{mg} \mathrm{H}_{3} \mathrm{BO}_{3}, 1 \mathrm{mg}$ $\left(\mathrm{NH}_{4}\right)_{6} \mathrm{Mo}_{7} \mathrm{O}_{24} \cdot 4 \mathrm{H}_{2} \mathrm{O}, 0.4 \mathrm{mg} \mathrm{CoCl} 2 \cdot 6 \mathrm{H}_{2} \mathrm{O}, 1 \mathrm{mg}$ 4-Aminobenzoic acid, $0.3 \mathrm{~g}$ Inositol, $1 \mathrm{mg}$ Vitamin B1 (Thiamine), $1 \mathrm{mg}$ Vitamin B3 (Nicotinic acid), $1 \mathrm{mg}$ Vitamin B5 (Pantothenic Acid), $1 \mathrm{mg}$ Vitamin B6 (Pyridoxine), and $0.04 \mathrm{mg}$ Vitamin $\mathrm{H}$ (Biotin). The $\mathrm{pH}$ was adjusted to 3.5 with $\mathrm{KOH}$.

Cultures of the four non-Saccharomyces yeast isolates and EC1118 were pre-incubated in $10 \mathrm{~mL}$ of YPD medium $(10 \mathrm{~g} / \mathrm{L}$ yeast extract, $20 \mathrm{~g} / \mathrm{L}$ peptone, and $20 \mathrm{~g} / \mathrm{L}$ glucose $)$ at $28^{\circ} \mathrm{C}$ in a rotary shaker $(100 \mathrm{rpm})$ for $48 \mathrm{~h}$ in order to get an inoculum size of $10^{7} \mathrm{CFU} / \mathrm{mL}$. Then, the SGJ was inoculated with $1 \%(v / v)$ of the pre-cultures and incubated at $28^{\circ} \mathrm{C}(100 \mathrm{rpm})$ for fermentation. The flasks were sealed with 8 layers of sterile gauze in order to allow the release of $\mathrm{CO}_{2}$ and also to prevent external microbial contamination. The fermentation processes of the four non-Saccharomyces yeast isolates and EC1118 were monitored daily by measuring the weight loss until the end of the fermentation (less than $0.10 \mathrm{~g}$ of weight loss for three consecutive days).

\subsection{Oenological Parameters Analysis}

The oenological parameters including the reducing (residual) sugar concentration, alcohol content, $\mathrm{pH}$, total acidity concentration (expressed as tartaric acid), and volatile acidity concentration (expressed as acetic acid) were measured according to the National Standard of the People's Republic of China: GB/T 15038-2006, Analytical Methods of Wine and Fruit Wine. The concentration of reducing sugar was determined by using the 3,5dinitrosalicylic acid method. The content of alcohol was determined by utilizing the density method. The concentration of the total acidity was determined by titration using standard sodium hydroxide $(0.05 \mathrm{M})$. The separation of volatile acidity from the wine was carried out by steam distillation and the concentration of volatile acidity was titrated by standard sodium hydroxide $(0.05 \mathrm{M})$. The value of $\mathrm{pH}$ was determined by a $\mathrm{pH}$ meter.

\subsection{Volatile Aroma Compounds Analysis}

The volatile aroma compounds in the five fermented media and SGJ were determined using the method that was reported by Zhang [22], with some modifications.

The volatiles were extracted by using the headspace solid phase microextraction (HS-SPME) method. Briefly, the fermented medium (5 mL), NaCl $(1.0 \mathrm{~g})$, and internal standard (4-methyl-2-pentanol, with a final concentration of $2030 \mu \mathrm{g} / \mathrm{L}$ ) were blended in a $15 \mathrm{~mL}$ airtight vial with PTFE/Silicone septa (27159, Supelco, Bellefonte, PA, USA) containing a magnetic stirrer. After being equilibrated at $40^{\circ} \mathrm{C}$ for $30 \mathrm{~min}$ under a rotational speed of $250 \mathrm{rpm}$, the sample was extracted by an SPME manual device (57330-U, Supelco, Bellefonte, PA, USA) that was equipped with DVB/CAR/PDMS fiber (57328-U, Supelco, Bellefonte, PA, USA) for $30 \mathrm{~min}$ with continued heating and rotation. Afterward, fiber was inserted into the GC injection port to desorb for $10 \mathrm{~min}$ at $250{ }^{\circ} \mathrm{C}$ (splitless model) and begin the GC-MS analysis.

The separation and identification of the volatiles were achieved in an Agilent 7890B GC system that was coupled with an Agilent 5977A MS detector and equipped with a DB-Wax capillary column $(60 \mathrm{~m} \times 0.250 \mathrm{~mm}$ i.d., $0.25 \mu \mathrm{m}$ df, J\&W scientific, Agilent, Santa Clara, CA, USA). Ultra-pure helium (99.999\%) was used as a carrier gas at a flow 
rate of $1 \mathrm{~mL} / \mathrm{min}$. The temperature program that was used was as follows: the process started at $50{ }^{\circ} \mathrm{C}$ for $1 \mathrm{~min}$ and then increased to $220^{\circ} \mathrm{C}$ at $3{ }^{\circ} \mathrm{C} / \mathrm{min}$ with a final holding time of $5 \mathrm{~min}$; the total run time was $62.7 \mathrm{~min}$. The temperature of the injector, transfer line, and ion source was set to $250{ }^{\circ} \mathrm{C}$. The mass spectra were obtained using a mass selective detector (MSD) working in electronic impact at $70 \mathrm{eV}$ in scan mode with a mass range of 30-350 $\mathrm{m} / \mathrm{z}$.

The identification of the volatiles was done by comparing the retention indices (RIs) and mass spectra with those of the pure standards as sourced from the NIST Chemistry WebBook (https: / / webbook.nist.gov/, accessed on 2 December 2021) and the standard NIST 14 library. The RIs were calculated using the $C_{10}-C_{24}$ alkane standard mixture (all even, soluble in heptane) (Sigma, city, Switzerland) under the same chromatographic conditions as the fermented media.

The quantitative analysis was performed using the internal standard-standard curve method; 4-methyl-2-pentanol was used as the internal standard and the standard curve was plotted using the 5-point method. According to the alcohol content, total acidity concentration, and $\mathrm{pH}$ in the fermented media, two kinds of synthetic model wine solution $(1.0 \%$ and $8.0 \% v / v$ alcohol content, $5.0 \mathrm{~g} / \mathrm{L}$ tartaric acid, and adjusted $\mathrm{pH}$ to 3.4 with $\mathrm{KOH}$ ) were prepared. All of the pure standards were dissolved in ethanol together and then this mixed solution was diluted to different levels with the synthetic model wine solutions. The mixed standards of each level were extracted and analyzed under the same conditions as the fermented media. When a volatile standard was a mixture of two isomers (e.g., $\beta$-Ocimene), the total areas of these two isomers were employed to plot the standard curve. When plotting a volatile compound for which there was no pure standard, the concentration of it was estimated by the standard curve of the standard compound with the most similar chemical structure or expressed as relative amount compared to the internal standard. The quantitative standard curves of each compound are listed in Table S2.

\subsection{Odor Activity Values (OAVs) and Aroma Series Analysis}

The odor activity values (OAVs), a commonly used parameter for the evaluation of the contribution of volatiles to wine aroma [23-26], were calculated and expressed as the ratio between the concentration of an individual compound and its perception threshold.

To predict the overall aroma profile of the fermented media from the GC-MS analysis data, the aroma-active compounds were grouped into six aroma series based on similar odor descriptions. These six aroma series were modeled from the literature [23,25-30], they included fruity, floral, herbaceous (green), balsamic, solvent, and fatty.

Due to the high complexity of olfactory descriptions, some aroma-active compounds might be included in two or more aroma series $[25,29,30]$. The total intensities for each aroma series were calculated by accumulating the OAVs of the individual compounds that belonged to each series, as listed in Table 3 (the compounds with OAVs > 1.0).

\subsection{Statistical Analysis}

All of the data were subjected to a one-way analysis of variance (ANOVA) that was performed through the IBM SPSS statistics 19.0 software package (SPSS Inc., Chicago, IL, USA.) employing Duncan multiple range tests at a significance level of $p<0.05$. The results were expressed as the mean value \pm the standard deviation. The principal component analysis (PCA) was performed through Origin 2018 (OriginLab Corporation, Northampton, MA, USA).

\section{Results and Discussion}

\subsection{Fermentation Kinetics and Oenological Parameters Analysis}

The fermentation kinetics of the five yeasts and the oenological parameters of the resultant fermented media are shown in Figure 1 and Table 1, respectively. The four nonSaccharomyces yeast isolates exhibited lower fermentative capacity when compared with the $S$. cerevisiae yeast EC1118. This observation was consistent with those of many other 
non-Saccharomyces yeasts that have been reported in previous studies [31,32]. Sat. diversa (BZL-11) showed the highest fermentation capacity among the four non-Saccharomyces yeast isolates, with $8.41 \%$ abv produced from $90.6 \%$ reducing sugars in SGJ within 9 days. In contrast, Sac. vini (BZL-28) barely started the fermentation with only $0.06 \%$ abv produced at the end of fermentation. M. guilliermondii (AD-58) and W. anomalus (DR-110) exhibited an intermediate fermentative behavior. In addition, these non-Saccharomyces yeast isolates showed a lower rate of conversion of sugar to alcohol (Table 1), which indicated that they might be potentially used for low-alcohol wine production [3,4].Compared with that which was fermented by EC1118 $(0.25 \mathrm{~g} / \mathrm{L})$, a higher level of volatile acidity was observed in the media that was fermented by the four non-Saccharomyces yeast isolates (ranging between 0.44 and $1.97 \mathrm{~g} / \mathrm{L}$ ), particularly in those that were fermented by M. guilliermondii (AD-58) and W. anomalus (DR-110). This may also explain the higher concentration of the total acidity in these two fermented media. As reported previously, the excessive production of volatile acidity is the main problem for most of the non-Saccharomyces yeasts $[10,31,33]$. Co-inoculation of non-Saccharomyces yeasts with S. cerevisiae [3,7] and reducing the oxygen saturation during fermentation [34] could be used to reduce the yield of volatile acidity from non-Saccharomyces yeasts.

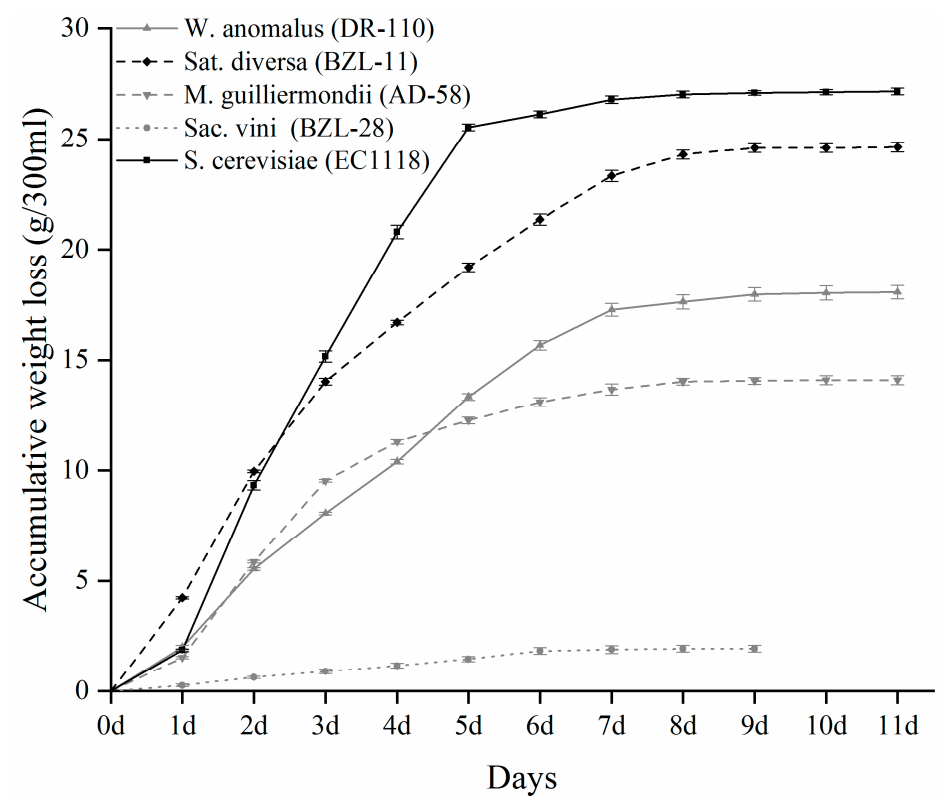

Figure 1. Fermentation kinetics of four indigenous non-Saccharomyces yeast isolates and EC1118 in SGJ.

\subsection{Volatile Aroma Compounds Analysis}

A total of 62 volatile aroma compounds were detected in the four non-Saccharomyces yeast isolates and EC1118 fermented media and the SGJ by HS-SPME-GC-MS. These volatile aroma compounds can be classified into six groups, including alcohols (16), esters (21), terpenes (10), fatty acids (5), carbonyl (8), and others (2). The qualitative and quantitative information of these aroma compounds are listed in Table 2 . The odor activity values (OAVs) of 22 key aroma compounds (with OAVs > 1.0) in the five fermented media and SGJ are listed in Table 3. As shown in Table 2, very few volatile aroma compounds were detected in the SGJ. This result indicated that the aroma production characteristics of the four indigenous non-Saccharomyces yeast isolates could be objectively evaluated by the SGJ fermentation, since the aroma compositions of their fermented media were not affected by the varietal aromas that derived from the natural grape juice. 
Table 1. Oenological parameter analysis of five fermented media and SGJ (mean \pm SD).

\begin{tabular}{|c|c|c|c|c|c|c|}
\hline & $\begin{array}{l}\text { M. guilliermondii } \\
\text { (AD-58) }\end{array}$ & $\begin{array}{l}\text { Sat. diversa } \\
\text { (BZL-11) }\end{array}$ & $\begin{array}{l}\text { Sac. vini } \\
\text { (BZL-28) }\end{array}$ & $\begin{array}{l}\text { W. anomalus } \\
\text { (DR-110) }\end{array}$ & $\begin{array}{l}\text { S. cerevisiae } \\
\text { (EC1118) }\end{array}$ & $\begin{array}{c}\text { SGJ } \\
\text { (Uninoculated) }\end{array}$ \\
\hline $\begin{array}{l}\text { Reducing (residual) } \\
\quad \text { sugar }(\mathrm{g} / \mathrm{L})\end{array}$ & $88.06 \pm 2.19 b$ & $16.35 \pm 1.12 \mathrm{~d}$ & $\begin{array}{c}167.28 \pm \\
1.44 \mathrm{a}\end{array}$ & $57.73 \pm 1.53 c$ & $0.75 \pm 0.01 \mathrm{e}$ & $173.66 \pm 0.87$ \\
\hline $\begin{array}{l}\text { Alcohol content } \\
(\% v / v)\end{array}$ & $4.40 \pm 0.08 \mathrm{~d}$ & $8.41 \pm 0.02 b$ & $0.06 \pm 0.02 \mathrm{e}$ & $5.39 \pm 0.03 c$ & $9.54 \pm 0.05 a$ & $0.01 \pm 0.01$ \\
\hline $\mathrm{pH}\left(20^{\circ} \mathrm{C}\right)$ & $3.42 \pm 0.01 b$ & $3.31 \pm 0.02 c$ & $3.50 \pm 0.02 \mathrm{a}$ & $3.32 \pm 0.01 c$ & $3.26 \pm 0.02 \mathrm{~d}$ & $3.50 \pm 0.02$ \\
\hline $\begin{array}{l}\text { Total acidity }(\mathrm{g} / \mathrm{L} \text { as } \\
\text { tartatic acid) }\end{array}$ & $5.86 \pm 0.04 a$ & $5.19 \pm 0.06 b$ & $3.28 \pm 0.04 \mathrm{~d}$ & $5.81 \pm 0.06 a$ & $4.93 \pm 0.04 c$ & $2.69 \pm 0.02$ \\
\hline $\begin{array}{l}\text { Volatile acidity ( } \mathrm{g} / \mathrm{L} \text { as } \\
\text { accetic acid) }\end{array}$ & $1.96 \pm 0.02 \mathrm{a}$ & $0.79 \pm 0.02 b$ & $0.44 \pm 0.00 c$ & $1.97 \pm 0.06 a$ & $0.25 \pm 0.02 \mathrm{~d}$ & $0.06 \pm 0.00$ \\
\hline $\begin{array}{l}\text { Reducing sugar } \\
\text { consumption }(\mathrm{g} / \mathrm{L})\end{array}$ & $85.59 \pm 2.19 d$ & $\begin{array}{c}157.31 \pm \\
1.12 b\end{array}$ & $6.37 \pm 1.44 \mathrm{e}$ & $115.93 \pm 1.53 c$ & $172.91 \pm 0.01 a$ & - \\
\hline $\begin{array}{l}\text { Sugars used for } 1 \% \\
\text { ethanol production }(\mathrm{g})\end{array}$ & 19.45 & 18.70 & 106.17 & 21.51 & 18.12 & - \\
\hline
\end{tabular}

Values followed by different letters in a row are significantly different $(p<0.05)$ by Duncan test.

ALCOHOLS. Higher alcohols (aliphatic and aromatic alcohols) are by-products of yeast metabolism during alcoholic fermentation. These compounds could add desirable complexity to the wine's aroma at a low concentration (below 300,000 $\mu \mathrm{g} / \mathrm{L}$ ), whereas they may have a detrimental effect when their concentration exceeds 400,000 $\mu \mathrm{g} / \mathrm{L}$ [35]. In the present work, the commercial S. cerevisiae yeast (EC1118) produced the highest total concentration of higher alcohols during the fermentation $(358,053.00 \mu \mathrm{g} / \mathrm{L})$, a result which was also observed in previous studies [7,32]. Whereas the total concentrations of higher alcohols that were generated by the four non-Saccharomyces yeast isolates were all below 300,000 $\mu \mathrm{g} / \mathrm{L}$ (ranging between 6833.32 and 221,829.74 $\mu \mathrm{g} / \mathrm{L}$ ), suggesting that these non-Saccharomyces yeast isolates could positively enhance the complexity of wine aroma. The major alcohols that were detected in this study were 1-propanol, 2-methyl-1-propanol, 3-methyl-1-butanol, 3-ethoxy-1-propanol, 3-methylthio-1-propanol, and 2-phenylethanol. Most of the major higher alcohols were detected at a higher level in the fermented media of Sat. diversa (BZL-11) and W. anomalus (DR-110). Of those higher alcohols, the concentration of 2-phenylethanol $(63,510.12 \mu \mathrm{g} / \mathrm{L})$ was determined to be present at a significantly higher level in the fermented medium of Sat. diversa (BZL-11). The lowest concentration of higher alcohols was observed in the fermented medium of Sac. vini (BZL-28) due to its weak fermentative capability (Table 2 ).

The 2,3-butanediol represents the most abundant volatile by-product of alcoholic fermentation and can affect both the bouquet of the wine due to its bitter taste and the body of the wine due to its viscosity [36]. In the present study, two isomers of 2,3-butanediol (the R,R- and R,S-form) were detected (except for in the medium that was fermented by Sac. vini). As shown in Table 2, the $S$. cerevisiae yeast (EC1118) exhibited a strong capacity for 2,3-butanediol production $(576,699.62$ and $122,089.94 \mu \mathrm{g} / \mathrm{L}$ for 2R,3R-butanediol and 2R,3Sbutanediol, respectively), which was in agreement with the results that were reported by Romano [36]. W. anomalus (DR-110) showed a similar capability of 2,3-butanediol production as EC1118 with regard to the ratio of the two isomers and the total concentration of 2,3-butanediol (Table 2). M. guilliermondii (AD-58) also produced a high level of 2,3butanediol during fermentation with more than $90 \%$ of the R,R-form of 2,3-butanediol $(537,151.25 \mu \mathrm{g} / \mathrm{L})$. These two isomers of 2,3-butanediol were observed at a relatively low level in the fermented medium of Sat. diversa (BZL-11), despite the fact that this yeast exhibited a greater alcoholic fermentation capability. On must take into account that the fermented medium of Sat. diversa (BZL-11) contained a relatively high level of acetoin $(25,524.16 \mu \mathrm{g} / \mathrm{L})$, the precursor of 2,3-butanediol, which could be explained by the relatively low activity of the acetoin reductase in Sat. diversa (BZL-11). 
EASTER. Esters have long been regarded as important contributors to wine aroma because they are the primary source of fruity aromas [37]. In the present study, a total of 21 esters were detected in the fermented media of the four non-Saccharomyces yeast isolates and EC1118. As shown in Table 2, ethyl acetate was the most abundant ester in the five fermented media. The highest concentration of this compound $(143,023.77 \mu \mathrm{g} / \mathrm{L})$ was observed in the medium that was fermented by W. anomalus (DR-110), which was approximately 7-fold higher than that which was found in the medium that was fermented by EC1118 (19,384.40 $\mu \mathrm{g} / \mathrm{L})$. Additionally, W. anomalus (DR-110) produced the most abundant esters during fermentation and some of these esters were exclusively found in its fermented medium, notably fatty acid esters of higher alcohols (Table 2). However, these compounds were not detected in apple cider that was fermented by W. anomalus (YN6) [38]. This could be explained by the difference of the ester metabolisms among different $W$. anomalus strains or the difference of the components between apple juice and SGJ. Therefore, the distinctive ester production ability of $W$. anomalus (DR-110) requires further study. Acetate esters and fatty acid ethyl esters were the primary esters that were detected in the fermented medium of EC1118, which is in agreement with previous studies [32,39]. The esters that were identified in the fermented medium of Sat. diversa (BZL-11) were similar to those of EC1118 but with a much lower concentration (Table 2). The exclusive presence of geranyl acetate in the fermented medium of Sac. Vini (BZL-28) could be related to the high production of geraniol of this isolate (Table 2). Concomitantly, according to the data that were obtained in the present study, M. guilliermondii (AD-58) seems not to be good at producing esters during fermentation.

TERPENES. Terpenes are the typical aroma compounds contributing to fruity (citriclike) and floral characters in wine [35] and they can exist as free and glycosylated precursors in grapes [40]. Although the SGJ that was used in the present work did not contain any free or glycosylated precursors of terpenes, several monoterpenes were still detected in the resultant fermented media of four of the yeasts, including M. guilliermondii (AD-58), Sat. diversa (BZL-11), Sac. vini (BZL-28), and S. cerevisiae (EC1118). This result was in agreement with previous studies which revealed that some $S$. cerevisiae and non-Saccharomyces yeasts have the ability of de novo biosynthesis of monoterpenes [40-42]. The concentrations of monoterpenes were determined at a trace level in the fermented media of M. guilliermondii (AD-58), Sat. diversa (BZL-11), and S. cerevisiae (EC1118) (Table 3), which is also in agreement with the results of previous studies [41,42]. In this study, Sac. vini (BZL-28) exhibited a notably high yield of terpenes during fermentation with more than ten monoterpenes having been detected in its fermented medium. Geraniol was the principal monoterpene, with the highest concentration at $1936.43 \mu \mathrm{g} / \mathrm{L}$, that was observed in the medium that was fermented by Sac. vini (BZL-28), which was nearly 65-fold higher than its sensory threshold of $30 \mu \mathrm{g} / \mathrm{L}$. In addition, (Z)- $\beta$-ocimene, (E)- $\beta$-ocimene, linalool, and citral also showed high OAVs in the medium that was fermented by Sac. vini (BZL-28) (Table 3). These results indicate that Sac. vini (BZL-28) could be used for improving the aroma of wines that are produced from neutral or low-aromatic grape varieties.

VOLATILE FATTY ACIDS. Volatile fatty acids are normally described as fatty, rancid, or cheesy odors (Table 2). They could contribute to the complexity of a wine's aroma at a low concentration under their sensory thresholds [35]. Among the five volatile fatty acids that were determined in the present work, short-chain fatty acids (isobutyric acid, butanoic acid, and isovaleric acid) were mainly detected in the fermented media of the non-Saccharomyces yeast isolates, with the highest concentration of short-chain fatty acids having been observed in the fermented medium of $W$. anomalus (DR-110) $(21,679.20 \mu \mathrm{g} / \mathrm{L}$ ). Medium-chain fatty acids, including octanoic acid and decanoic acid, were mainly detected in the fermented medium of EC1118. This result was consistent with a previous study that found that cherry wine that was fermented by S. cerevisiae yeasts (EC1118 and D254) showed higher levels of medium-chain fatty acids than those that were fermented by nonSaccharomyces yeasts (e.g., T. delbrueckii and M. pulcherrima) [32]. The ability of S. cerevisiae yeasts to produce medium-chain fatty acids may enhance their competitiveness during 
wine fermentation, since medium-chain fatty acids could inhibit the growth of some nonSaccharomyces yeasts and bacteria [43-45].

CARBONYL AND OTHER COMPOUNDS. In this study, two aldehydes (nonanal and benzaldehyde), six ketones (methyl isobutyl ketone, 3-penten-2-one, 5-methyl-2-hexanone, acetoin, 6-methyl-5-hepten-2-one, and 2-nonanone), 1-(1-ethoxyethoxy)-pentane, and $\gamma$ butyrolactone were determined in the fermented media of the four non-Saccharomyces yeast isolates and EC1118 (Table 2). Although differences in their concentrations were observed between the five fermented media, only the concentration of nonanal was determined at the level near to, or beyond, its sensory threshold of $15 \mu \mathrm{g} / \mathrm{L}$. As nonanal was also observed in the uninoculated SGJ, this aroma compound seems unlikely to be associated with the fermentation of these yeasts.

\subsection{PCA Analysis of Key Aroma Compounds}

For the principal component analysis (PCA), the concentrations of 22 key aroma compounds were used to build up the data matrix and the distribution of the fermented media based on these key aroma compounds (Figure 2). A total of $72.4 \%$ variance was generated by the first two principal components, where $39.5 \%$ and $32.9 \%$ of the variance were explained by PC1 and PC2, respectively (Figure 2A). According to the proximity of these samples on the score plot, the fermented media of the four non-Saccharomyces yeast isolates and EC1118 were divided into four groups (Figure 2B). The fermented medium of EC1118 was located in the 3rd quadrant (Group 1) due to its greater ability to produce volatile aroma compounds such as 3-ethoxy-1-propanol, ethyl hexanoate, ethyl octanoate, octanoic acid, and decanoic acid. Group 2 was formed by the fermented medium of W. anomalus (DR110), which showed greater production of ethyl acetate, ethyl 2-methylpropanoate, ethyl 2-methylbutyrate, ethyl 3-methylbutyrate, isobutyric acid, butanoic acid, and isovaleric acid. Group 3 was located in the 1st quadrant and was mainly formed by the fermented medium of Sac. vini (BZL-28), which showed greater production of $(Z)-\beta$-ocimene, $(E)-\beta$ ocimene, linalool, citral, and geraniol. The uninoculated SGJ and the fermented media of M. guilliermondii (AD-58) and Sat. diversa (BZL-11) were closely grouped together due to their low concentrations of most of the volatile compounds.

\subsection{Aroma Profile Analysis of Resultant Fermented Media}

To understand the composition of the different aroma series (categories) in each of the individual fermented media, the total OAV ( $\Sigma \mathrm{OAVs}$ ) was calculated by summing up the OAVs of the individual compounds (with OAVs > 1.0) belonging to each aroma series (Table 3). As shown in Figure 3, the fermented media of the four non-Saccharomyces yeast isolates exhibited completely different aroma profiles when compared with the fermented medium of EC1118, which was primarily characterized by a fruity aroma. The fermented medium of $W$. anomalus (DR-110) was largely characterized by a fatty aroma due to its high production of short-chain fatty acids and a fruity aroma due to its great production of esters. The fermented medium of Sac. vini (BZL-28) was largely characterized by fruity (citrus-like) and floral aromas, which were related to its high concentration of monoterpenes. The fermented medium of Sat. diversa (BZL-11) was also characterized by fruity and fatty aromas, but with much lower $\Sigma \mathrm{OAV}$ s compared with the medium that was fermented by $W$. anomalus (DR-110). No distinctive aroma was observed in the fermented medium of M. guilliermondii (AD-58) due to the very low OAVs of most of the volatiles (Table 3). 
Table 2. Concentrations of volatile aroma compounds in five fermented media and SGJ (mean \pm SD).

\begin{tabular}{|c|c|c|c|c|c|c|c|c|c|c|}
\hline \multirow[b]{2}{*}{ No. } & \multirow[b]{2}{*}{$\mathbf{R I}^{\mathrm{a}}$} & \multirow[b]{2}{*}{ Compounds $^{b}$} & \multicolumn{6}{|c|}{ Concentrations $(\mu \mathrm{g} / \mathrm{L})$} & \multirow{2}{*}{$\begin{array}{c}\text { Odor } \\
\text { Threshold } \\
(\mu \mathrm{g} / \mathrm{L})^{\mathrm{c}}\end{array}$} & \multirow[b]{2}{*}{ Odor Description ${ }^{\mathrm{d}}$} \\
\hline & & & $\begin{array}{l}\text { M. guilliermondii } \\
\text { (AD-58) }\end{array}$ & $\begin{array}{l}\text { Sat. diversa } \\
\text { (BZL-11) }\end{array}$ & $\begin{array}{l}\text { Sac. vini } \\
\text { (BZL-28) }\end{array}$ & $\begin{array}{l}\text { W. anomalus } \\
\text { (DR-110) }\end{array}$ & $\begin{array}{l}\text { S. cerevisiae } \\
\text { (EC1118) }\end{array}$ & $\begin{array}{c}\text { SGJ } \\
\text { (Uninoculated) }\end{array}$ & & \\
\hline 1 & 1036 & 1-Propanol A & $8408.27 \pm 197.62^{c}$ & $2284.48 \pm 57.42^{\mathrm{d}}$ & $759.35 \pm 34.64^{\mathrm{d}}$ & $18,813.98 \pm 1067.56^{\mathrm{b}}$ & $42,118.28 \pm 2014.65^{a}$ & nd & $306,000[29,30]$ & $\begin{array}{c}\text { Alcohol, ripe fruit } \\
\text { [30] }\end{array}$ \\
\hline 2 & 1085 & 2-Methyl-1-propanol A & $16,932.19 \pm 561.49^{d}$ & $26,174.41 \pm 675.13^{c}$ & $\operatorname{tr}$ & $31,727.84 \pm 1142.44^{\mathrm{b}}$ & $37,657.46 \pm 2447.08^{a}$ & nd & $40,000[46]$ & $\begin{array}{c}\text { Alcohol, solvent } \\
\text { [30] }\end{array}$ \\
\hline 3 & 1142 & Butanol $^{\mathrm{A}}$ & nd & nd & nd & $168.30 \pm 9.33$ & nd & nd & $150,000[29,30]$ & $\begin{array}{l}\text { Medicinal, phenolic } \\
{[30]}\end{array}$ \\
\hline 4 & 1213 & 3-Methyl-1-butanol A & $21,680.11 \pm 530.17^{c}$ & $129,185.54 \pm 8171.46^{\mathrm{b}}$ & $5572.99 \pm 496.70^{\mathrm{c}}$ & $130,776.34 \pm 2122.26^{b}$ & $250,240.90 \pm 13,174.17^{\mathrm{a}}$ & nd & $30,000[46]$ & $\begin{array}{c}\text { Alcohol, nail polish } \\
\text { [30] }\end{array}$ \\
\hline 5 & 1254 & $\underset{\mathrm{A}}{\text { 3-Methyl-3-buten-1-ol }}$ & $25.44 \pm 3.09^{\mathrm{b}}$ & $25.42 \pm 4.88^{\mathrm{b}}$ & nd & $50.95 \pm 5.72^{\mathrm{a}}$ & nd & nd & $600[24]$ & Alcohol, solvent * \\
\hline 6 & 1333 & 3-Methyl-1-pentanol A & nd & $32.15 \pm 3.63^{b}$ & nd & $22.03 \pm 0.54^{\mathrm{c}}$ & $62.44 \pm 3.57^{\mathrm{a}}$ & nd & $1000[29,30]$ & Green, solvent [30] \\
\hline 7 & 1386 & 3-Ethoxy-1-propanol A & $\operatorname{tr}$ & nd & nd & $\operatorname{tr}$ & $528.73 \pm 20.45$ & nd & $100[29,30]$ & Fruity [30] \\
\hline 8 & 1498 & 2-Ethyl-1-hexanol ${ }^{\mathrm{A}}$ & $5.80 \pm 0.12^{b}$ & $8.41 \pm 0.93^{\mathrm{a}}$ & $2.16 \pm 0.07^{c}$ & $5.95 \pm 0.03^{b}$ & $4.82 \pm 0.07^{b c}$ & $2.33 \pm 0.09$ & $8000[24]$ & Waxy, soapy * \\
\hline 9 & 1527 & 2-Nonanol C & nd & nd & $8.01 \pm 0.24^{b}$ & nd & $11.52 \pm 0.27^{\mathrm{a}}$ & nd & $\mathrm{NF}$ & Green [26] \\
\hline 10 & 1566 & Octanol $^{\mathrm{A}}$ & nd & nd & nd & $5.62 \pm 0.15^{\mathrm{a}}$ & $5.31 \pm 0.25^{\mathrm{a}}$ & $4.37 \pm 0.03$ & $800[29,30]$ & $\begin{array}{c}\text { Lemon, jasmine } \\
{[30]}\end{array}$ \\
\hline 12 & 1730 & $\begin{array}{l}\text { 3-Methylthio-1- } \\
\text { propanol } \\
\text { A }\end{array}$ & nd & $472.82 \pm 57.90^{\mathrm{b}}$ & nd & $497.08 \pm 15.85^{\mathrm{b}}$ & $730.88 \pm 14.66^{\mathrm{a}}$ & nd & $1000[47]$ & $\begin{array}{l}\text { Cooked potato, } \\
\text { garlic [30] }\end{array}$ \\
\hline 13 & 1891 & Benzyl alcohol A & $\operatorname{tr}$ & $136.39 \pm 12.53^{\mathrm{b}}$ & $240.85 \pm 24.83^{\mathrm{a}}$ & nd & nd & nd & $900,000[29,30]$ & Toasted [30] \\
\hline \multirow[t]{2}{*}{14} & 1928 & 2-Phenylethanol ${ }^{\mathrm{A}}$ & $3743.17 \pm 137.52^{\mathrm{d}}$ & $63,510.12 \pm 2979.73^{a}$ & $242.53 \pm 51.51^{\mathrm{e}}$ & $17,405.83 \pm 404.72^{c}$ & $26,692.65 \pm 439.28^{\mathrm{b}}$ & nd & $10,000[46]$ & Roses [30] \\
\hline & & $\sum$ Higher alcohols & $50,802.02 \pm 1261.85^{\mathrm{d}}$ & $221,829.74 \underset{\mathrm{b}}{ \pm} 11,647.04$ & $6833.32 \pm 583.81^{\mathrm{e}}$ & $199,481.44 \pm 3552.16^{c}$ & $358,053.00 \pm 13,985.63^{\mathrm{a}}$ & $6.70 \pm 0.12$ & & \\
\hline 1 & 1549 & 2R,3R-Butanediol C & $537,151.25 \underset{\mathrm{b}}{ \pm} 44,873.06$ & $231,750.33_{\mathrm{c}}^{ \pm} 12,660.86$ & nd & $622,811.33 \underset{\mathrm{a}}{ \pm} \underset{29,652.85}{2}$ & $576,699.62 \pm 24,216.94 \mathrm{ab}$ & nd & $150,000[29,30]$ & Fruity [30] \\
\hline \multirow[t]{2}{*}{2} & 1585 & 2R,3S-Butanediol ${ }^{\mathrm{A}}$ & $55,984.92 \pm 4112.28^{\mathrm{b}}$ & $25,422.53 \pm 839.23^{c}$ & nd & $130,128.37 \pm 7072.80^{\mathrm{a}}$ & $122,089.94 \pm 4230.99^{\mathrm{a}}$ & nd & $150,000[29,30]$ & Fruity [30] \\
\hline & & $\sum$ Polyols & $\underset{\mathrm{b}}{593,136.16} \underset{\mathrm{b}}{48,953.50}$ & $257,172.86 \underset{\mathrm{c}}{ \pm} 13,477.34$ & & $752,939.70 \pm 36590.38^{a}$ & $698,789.56 \pm 26,073.88^{a}$ & & & \\
\hline 1 & 933 & Ethyl acetate ${ }^{\mathrm{A}}$ & $6706.40 \pm 319.00^{\mathrm{d}}$ & $1735.61 \pm 234.45^{\mathrm{d}}$ & $74,106.81 \pm 2945.79^{b}$ & $143,023.77 \pm 4894.98^{\text {a }}$ & $19,384.40 \pm 886.41^{\mathrm{c}}$ & $\operatorname{tr}$ & $7500[46]$ & $\begin{array}{c}\text { Pineapple, varnish, } \\
\text { balsamic [30] }\end{array}$ \\
\hline 2 & 985 & Propyl acetate ${ }^{\mathrm{A}}$ & $\operatorname{tr}$ & nd & $13.05 \pm 0.88^{b}$ & $108.02 \pm 2.57^{\mathrm{a}}$ & nd & nd & $4700[29,30]$ & Celery [29] \\
\hline 3 & 1118 & 3-Methylbutyl acetate & $50.89 \pm 3.62^{c}$ & $14.22 \pm 3.52^{c}$ & $106.22 \pm 27.76^{c}$ & $507.00 \pm 25.80^{a}$ & $376.16 \pm 22.71^{b}$ & nd & $30[46]$ & Fruity, sweet [30] \\
\hline
\end{tabular}


Table 2. Cont.

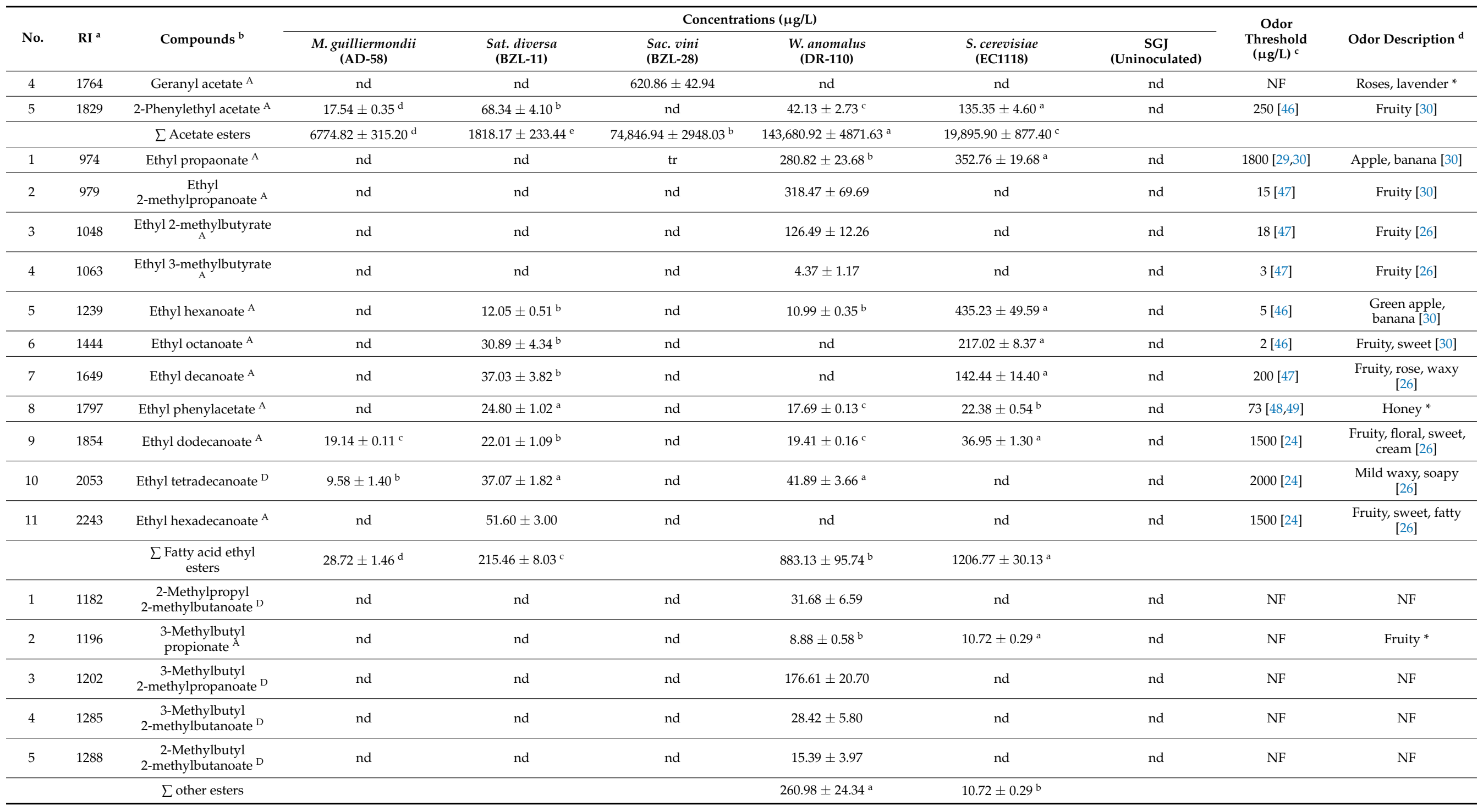


Table 2. Cont.

\begin{tabular}{|c|c|c|c|c|c|c|c|c|c|c|}
\hline \multirow[b]{2}{*}{ No. } & \multirow[b]{2}{*}{$\mathbf{R I}^{\mathrm{a}}$} & \multirow[b]{2}{*}{ Compounds $^{b}$} & \multicolumn{6}{|c|}{ Concentrations $(\mu \mathrm{g} / \mathrm{L})$} & \multirow{2}{*}{$\begin{array}{c}\text { Odor } \\
\text { Threshold } \\
(\mu \mathrm{g} / \mathrm{L})^{\mathrm{c}}\end{array}$} & \multirow[b]{2}{*}{ Odor Description ${ }^{\mathrm{d}}$} \\
\hline & & & $\begin{array}{c}\text { M. guilliermondii } \\
\text { (AD-58) }\end{array}$ & $\begin{array}{l}\text { Sat. diversa } \\
\text { (BZL-11) }\end{array}$ & $\begin{array}{l}\text { Sac. vini } \\
\text { (BZL-28) }\end{array}$ & $\begin{array}{l}\text { W. anomalus } \\
\text { (DR-110) }\end{array}$ & $\begin{array}{l}\text { S. cerevisiae } \\
\text { (EC1118) }\end{array}$ & $\begin{array}{c}\text { SGJ } \\
\text { (Uninoculated) }\end{array}$ & & \\
\hline 1 & 1163 & $\beta$-Myrcene ${ }^{A}$ & nd & nd & $68.38 \pm 6.19$ & nd & nd & nd & $100[49]$ & Lemon, pine* \\
\hline 2 & 1207 & D-Limonene $^{\mathrm{A}}$ & nd & nd & $22.70 \pm 1.33$ & nd & nd & nd & $200[49]$ & $\begin{array}{c}\text { Citrus, floral, green } \\
{[28]}\end{array}$ \\
\hline 3 & 1238 & $(Z)$ - $\beta$-Ocimene ${ }^{\mathrm{B}}$ & nd & nd & $111.25 \pm 10.62$ & nd & nd & nd & 34 [49] & Fruity [28] \\
\hline 4 & 1256 & $(E)$ - $\beta$-Ocimene ${ }^{\mathrm{B}}$ & nd & nd & $175.79 \pm 18.76$ & nd & nd & nd & 34 [49] & Fruity [28] \\
\hline 5 & 1554 & Linalool $^{\mathrm{A}}$ & nd & nd & $28.75 \pm 2.09$ & nd & nd & nd & $15[46]$ & Citrus, floral [30] \\
\hline 7 & 1745 & Citral $^{\mathrm{A}}$ & nd & nd & $375.83 \pm 28.54$ & nd & nd & nd & $85.3[50]$ & Citrus* \\
\hline 8 & 1774 & Citronellol $^{\mathrm{A}}$ & $10.47 \pm 0.29^{b}$ & nd & $87.28 \pm 3.96^{a}$ & nd & $17.89 \pm 0.58^{\mathrm{b}}$ & nd & $100[46]$ & Rose [30] \\
\hline 9 & 1810 & $\mathrm{Nerol}^{\mathrm{A}}$ & $15.74 \pm 0.10^{\mathrm{b}}$ & $15.89 \pm 0.03^{\mathrm{b}}$ & $33.30 \pm 2.71^{\mathrm{a}}$ & nd & nd & nd & $700[48,51]$ & Floral [25] \\
\hline \multirow[t]{2}{*}{10} & 1858 & Geraniol $^{\mathrm{A}}$ & $19.35 \pm 0.22^{\mathrm{b}}$ & $21.38 \pm 0.17^{b}$ & $1936.43 \pm 192.70^{\mathrm{a}}$ & nd & nd & nd & $30[46]$ & $\begin{array}{c}\text { Citrus, geranium } \\
\text { [25] }\end{array}$ \\
\hline & & $\sum$ Terpenes & $55.77 \pm 0.60^{\mathrm{b}}$ & $47.55 \pm 0.35^{\mathrm{b}}$ & $2849.23 \pm 230.50^{a}$ & & $17.89 \pm 0.58^{\mathrm{b}}$ & & & \\
\hline 1 & 1577 & Isobutyric acid ${ }^{\mathrm{A}}$ & $747.25 \pm 19.58^{\mathrm{e}}$ & $2775.14 \pm 171.63^{c}$ & $1029.00 \pm 22.92^{\mathrm{d}}$ & $15,624.12 \pm 558.72^{a}$ & $4988.69 \pm 437.36^{\mathrm{b}}$ & nd & $2300[47]$ & Fatty, rancid [30] \\
\hline 2 & 1638 & Butanoic acid $^{\mathrm{A}}$ & $173.67 \pm 2.98^{b}$ & $180.24 \pm 8.29^{b}$ & nd & $476.02 \pm 10.62^{\mathrm{a}}$ & nd & nd & $173[47]$ & Cheese, rancid [30] \\
\hline 4 & 2071 & Octanoic acid ${ }^{\mathrm{A}}$ & nd & $107.13 \pm 4.38^{b}$ & nd & nd & $1078.91 \pm 40.80^{\mathrm{a}}$ & nd & $500[47]$ & $\begin{array}{l}\text { Cheese, fatty, } \\
\text { rancid [30] }\end{array}$ \\
\hline \multirow[t]{2}{*}{5} & 2265 & Decanoic acid $^{\mathrm{D}}$ & nd & $76.66 \pm 12.37^{b}$ & nd & nd & $1613.53 \pm 137.53^{\text {a }}$ & nd & $1000[47]$ & Fatty, rancid [30] \\
\hline & & $\sum$ Fatty acids & $920.91 \pm 21.53^{\mathrm{d}}$ & $3658.18 \pm 207.93^{c}$ & $1029.00 \pm 22.92^{\mathrm{d}}$ & $21679.20 \pm 429.27^{a}$ & $7681.12 \pm 277.69^{b}$ & & & \\
\hline 1 & 1010 & 4-Methyl-2-pentanone & $234.09 \pm 9.33^{c}$ & $237.13 \pm 7.41^{\mathrm{c}}$ & $380.54 \pm 4.54^{\mathrm{b}}$ & $211.62 \pm 4.12^{\mathrm{d}}$ & $402.13 \pm 4.83^{\mathrm{a}}$ & nd & NF & NF \\
\hline 2 & 1130 & 3-Penten-2-one ${ }^{\mathrm{D}}$ & nd & $10.73 \pm 0.36$ & nd & nd & nd & nd & $\mathrm{NF}$ & $\mathrm{NF}$ \\
\hline 3 & 1187 & 5-Methyl-2-hexanone ${ }^{\mathrm{D}}$ & nd & nd & nd & nd & $34.00 \pm 1.42$ & 0.60 & $\mathrm{NF}$ & $\mathrm{NF}$ \\
\hline 4 & 1299 & Acetoin $^{\mathrm{A}}$ & $3480.97 \pm 395.35^{b}$ & $25524.16 \pm 3141.09^{a}$ & nd & $3911.90 \pm 632.45^{\mathrm{b}}$ & $\operatorname{tr}$ & nd & $150,000[29,30]$ & Cream, butter [30] \\
\hline 5 & 1344 & $\begin{array}{l}\text { 6-Methyl-5-hepten-2- } \\
\text { one } \\
\text { A }\end{array}$ & $1.72 \pm 0.01^{b}$ & $2.25 \pm 0.14^{a}$ & nd & nd & nd & nd & NF & Fruity * \\
\hline 6 & 1402 & Nonanal $^{\mathrm{A}}$ & $13.48 \pm 0.19^{c}$ & $13.85 \pm 0.57^{b c}$ & $13.98 \pm 0.21^{\mathrm{bc}}$ & $14.20 \pm 0.12^{b}$ & $15.12 \pm 0.21^{\mathrm{a}}$ & $13.10 \pm 0.05$ & 15 [23] & Green [28] \\
\hline 7 & 1396 & 2-Nonanone ${ }^{\mathrm{D}}$ & nd & nd & nd & nd & $194.55 \pm 22.07$ & nd & NF & NF \\
\hline 8 & 1535 & Benzaldehyde $^{\mathrm{A}}$ & $20.81 \pm 4.66^{\mathrm{d}}$ & $85.19 \pm 9.90^{b}$ & $59.36 \pm 7.83^{c}$ & $22.40 \pm 1.76^{\mathrm{d}}$ & $133.71 \pm 2.68^{\mathrm{a}}$ & $10.54 \pm 0.55$ & $2000[29,30]$ & Almond [31] \\
\hline
\end{tabular}


Table 2. Cont.

\begin{tabular}{|c|c|c|c|c|c|c|c|c|c|c|}
\hline \multirow[b]{2}{*}{ No. } & \multirow[b]{2}{*}{$\mathbf{R I}^{\mathrm{a}}$} & \multirow[b]{2}{*}{ Compounds ${ }^{b}$} & \multicolumn{6}{|c|}{ Concentrations $(\mu \mathrm{g} / \mathrm{L})$} & \multirow{2}{*}{$\begin{array}{c}\text { Odor } \\
\text { Threshold } \\
(\mu \mathrm{g} / \mathrm{L})^{\mathrm{c}}\end{array}$} & \multirow[b]{2}{*}{ Odor Description ${ }^{\mathrm{d}}$} \\
\hline & & & $\begin{array}{l}\text { M. guilliermondii } \\
\text { (AD-58) }\end{array}$ & $\begin{array}{l}\text { Sat. diversa } \\
\text { (BZL-11) }\end{array}$ & $\begin{array}{l}\text { Sac. vini } \\
\text { (BZL-28) }\end{array}$ & $\begin{array}{l}\text { W. anomalus } \\
\text { (DR-110) }\end{array}$ & $\begin{array}{l}\text { S. cerevisiae } \\
\text { (EC1118) }\end{array}$ & $\begin{array}{c}\text { SGJ } \\
\text { (Uninoculated) }\end{array}$ & & \\
\hline & & $\begin{array}{l}\sum \text { Carbonyl } \\
\text { compounds }\end{array}$ & $3751.07 \pm 399.99^{b}$ & $25,873.31 \pm 3145.56^{c}$ & $453.89 \pm 11.52^{\mathrm{d}}$ & $4160.11 \pm 631.12^{\mathrm{b}}$ & $779.51 \pm 24.21^{\mathrm{c}}$ & $24.23 \pm 0.60$ & & \\
\hline 1 & 1101 & $\begin{array}{l}\text { 1-(1-ethoxyethoxy)- } \\
\text { pentane } \\
\text { D }\end{array}$ & $11.46 \pm 0.53^{\mathrm{c}}$ & $832.32 \pm 85.35^{a}$ & nd & $215.96 \pm 14.16^{\mathrm{b}}$ & $288.58 \pm 44.78^{\mathrm{b}}$ & nd & NF & NF \\
\hline \multirow[t]{3}{*}{2} & 1643 & $\gamma$-Butyrolactone ${ }^{\mathrm{D}}$ & nd & $26.95 \pm 2.07$ & nd & nd & nd & nd & $20,000[29,30]$ & Caramel, sweet [29] \\
\hline & & $\sum$ Other compounds & $11.46 \pm 0.53^{c}$ & $859.27 \pm 87.25^{\mathrm{a}}$ & & $215.96 \pm 14.16^{b}$ & $288.58 \pm 44.78^{b}$ & & & \\
\hline & & $\begin{array}{c}\sum \text { All volatile aroma } \\
\text { compounds }\end{array}$ & $655,480.59 \underset{\mathrm{b}}{ \pm} 50,073.53$ & $511,474.53 \underset{c}{ \pm} 28,041.48$ & $86,012.36 \pm 2168.69^{d}$ & $\begin{array}{c}1,123,301.80 \pm \\
30,072.42^{\mathrm{a}}\end{array}$ & $1,086,723.08 \pm 39,911.55^{\mathrm{a}}$ & & & \\
\hline
\end{tabular}

Values followed by different letters in a row are significantly different $(p<0.05)$ by Duncan test. "nd" means not detected; "tr = trace" means could not be quantified. The concentrations of volatile aroma compounds in the fermented medium of Sac. vini (BZL-28) and in the SGJ (uninoculated) were calculated by using calibration curve plotted in 1.0\% ( $v / v$ ) model wine solution. The concentrations of volatile aroma compounds in the fermented media of M. guilliermondii (AD-58), Sat. diversa (BZL-11), W. anomalus (DR-110), and S. cerevisiae (EC1118) were calculated by using calibration curve plotted in $8.0 \%(v / v)$ model wine solution. ${ }^{\text {a }}$ : Retention indices (RIs) of compounds on DB-Wax capillary column. ${ }^{\text {b: }}$ Compounds quantified methods. A: calculated by internal standard-standard curve (plotted using corresponding standards); ${ }^{\mathrm{B}}$ : calculated by internal standard-standard curve (plotted using the total areas of

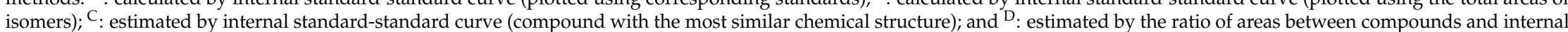
standard. c: odor threshold: [23]: Odor threshold value was determined in a synthetic wine (10\% $v / v$ ethanol, $5 \mathrm{~g} / \mathrm{L}$ tartaric acid, $\mathrm{pH} 3.2)$; [24]: Odor threshold values were determined in a synthetic wine (9.72 g/ $100 \mathrm{~g}$ water/ethanol, $5 \mathrm{~g} / \mathrm{L}$ tartaric acid, $\mathrm{pH} 3.2) ;[29,30]$ : Odor threshold values were determined in a synthetic wine (10\% $v / v$ ethanol, pH 3.5); [46]: Odor in a synthetic wine $(9.72 \mathrm{~g} / 100 \mathrm{~g}$ water/ethanol, $5 \mathrm{~g} / \mathrm{L}$ tartaric acid, $\mathrm{pH} 3.2) ;[29,30]$ : Odor threshold values were determined in a synthetic wine (10\% $v / v$ ethanol, $\mathrm{pH} 3.5) ;[46]$ : Odor
threshold values were determined in water/ethanol $(90 / 10, w / w) ;[47]$ : Odor threshold values were determined in a synthetic wine $(11 \% v / v$ ethanol, $7 \mathrm{~g} / \mathrm{L}$ glycerin, $5 \mathrm{~g} / \mathrm{L}$ tartaric acid, $\mathrm{pH}$ 3.4); [48]: Odor threshold value was determined in a basic red wine; [49]: Odor threshold values were determined in water; [50]: Odor threshold value was determined in water; [51]: Odor threshold value was determined in a synthetic wine ( $12 \% v / v$ ethanol, $5 \mathrm{~g} / \mathrm{L}$ tartaric acid, $\mathrm{pH}$ 3.5); and NF: Odor threshold values were not found in references. ${ }^{\mathrm{d}}$ : odor description: * Described in the laboratory according to the odor of standards, Yunnan Agricultural University, China. NF: Odor descriptions were not found in references or no standards for described the odor in the laboratory. 

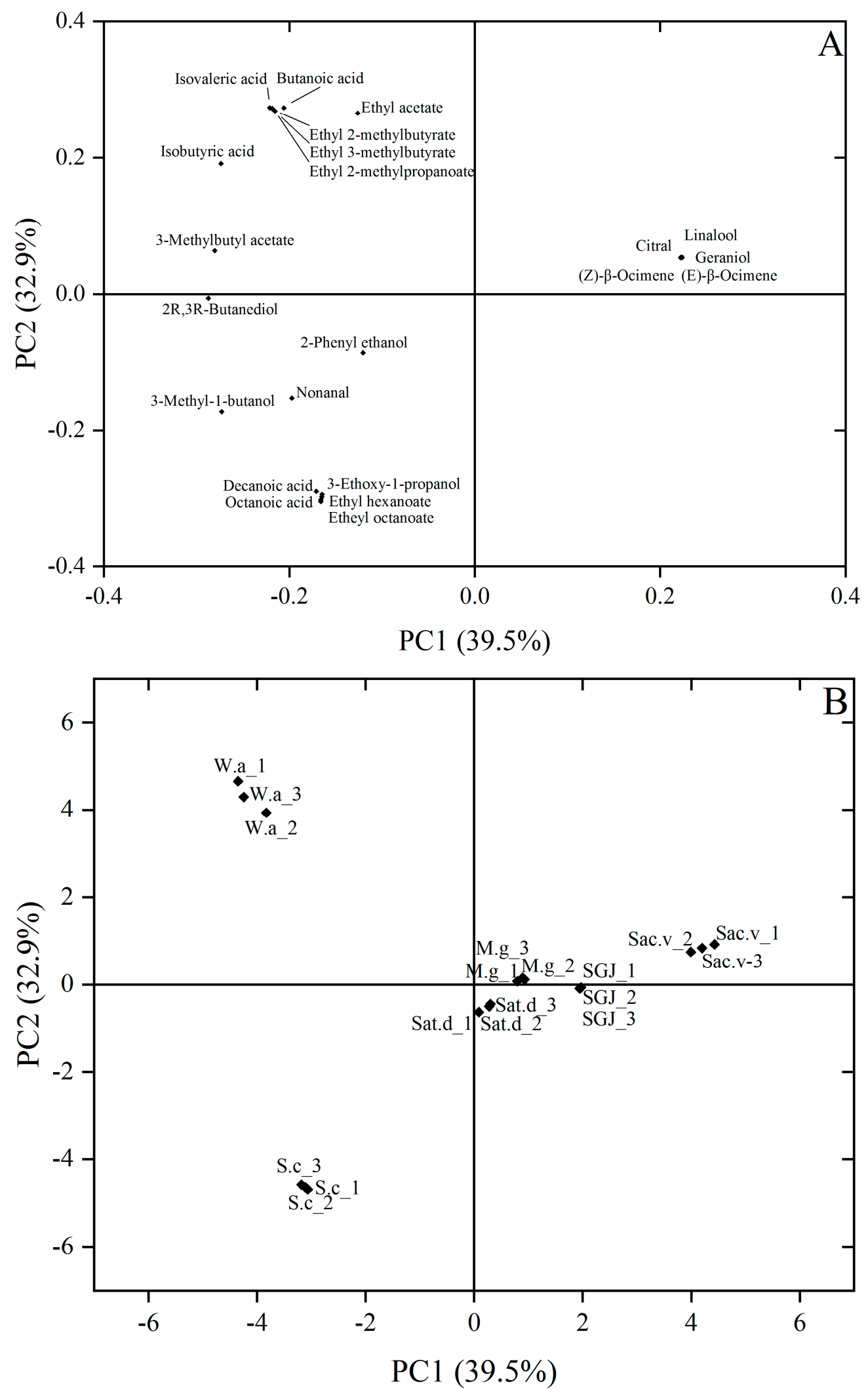

Figure 2. PCA analysis of key aroma compounds (A) and the distribution of five fermented media and SGJ (B) based on the first two principal components. M. g = M. guilliermondii (AD-58), Sat. $\mathrm{d}=$ Sat. diversa $($ BZL-11), Sac. $\mathrm{v}=$ Sac. vini $(\mathrm{BZL}-28), \mathrm{W} . \mathrm{a}=$ W. anomalus $(\mathrm{DR}-110), \mathrm{S} . \mathrm{c}=$ S. cerevisiae (EC1118), SGJ = Synthetic grape juice (uninoculated). 
Table 3. OAVs of key aroma compounds in five fermented media and SGJ.

\begin{tabular}{|c|c|c|c|c|c|c|c|c|}
\hline No. & Compounds & $\begin{array}{c}\text { M. guillier- } \\
\text { mondii(AD-58) }\end{array}$ & $\begin{array}{l}\text { Sat. diversa } \\
\text { (BZL-11) }\end{array}$ & $\begin{array}{l}\text { Sac. vini } \\
\text { (BZL-28) }\end{array}$ & $\begin{array}{l}\text { W. anomalus } \\
\text { (DR-110) }\end{array}$ & $\begin{array}{l}\text { S. cerevisiae } \\
\text { (EC1118) }\end{array}$ & $\begin{array}{c}\text { SGJ } \\
\text { (Uninoculated) }\end{array}$ & Aroma Series \\
\hline 1 & 3-Methyl-1-butanol & $0.72 \pm 0.02 c$ & $4.31 \pm 0.27 \mathrm{~b}$ & $0.19 \pm 0.02 \mathrm{~d}$ & $4.36 \pm 0.07 \mathrm{~b}$ & $8.34 \pm 0.44 a$ & - & Solvent [30] \\
\hline 2 & 3-Ethoxy-1-propanol & - & - & - & - & $5.29 \pm 0.20$ & - & Fruity [30] \\
\hline 3 & 2-Phenylethanol & $0.37 \pm 0.01 \mathrm{~d}$ & $6.35 \pm 0.30 \mathrm{a}$ & $0.02 \pm 0.01 \mathrm{e}$ & $1.74 \pm 0.04 c$ & $2.67 \pm 0.04 b$ & - & Floral [30] \\
\hline 4 & 2R,3R-Butanediol & $3.58 \pm 0.30 c$ & $1.55 \pm 0.08 \mathrm{~d}$ & & $4.15 \pm 0.20 \mathrm{a}$ & $3.84 \pm 0.16 b$ & - & Fruity [30] \\
\hline 5 & Ethyl acetate & $0.89 \pm 0.04 d$ & $0.23 \pm 0.03 e$ & $9.88 \pm 0.39 b$ & $19.07 \pm 0.65 a$ & $2.58 \pm 0.12 c$ & - & $\begin{array}{c}\text { Fruity, Balsamic, } \\
\text { Solvent [30] }\end{array}$ \\
\hline 6 & 3-Methylbutyl acetate & $1.70 \pm 0.12 \mathrm{~d}$ & $0.47 \pm 0.12 \mathrm{e}$ & $3.54 \pm 0.93 c$ & $16.90 \pm 0.86 a$ & $12.54 \pm 0.76 b$ & - & Fruity [30] \\
\hline 7 & Ethyl 2-methylpropanoate & - & - & - & $25.43 \pm 4.65$ & - & - & Fruity [30] \\
\hline 8 & Ethyl 2-methylbutyrate & - & - & - & $7.03 \pm 0.68$ & - & - & Fruity [26] \\
\hline 9 & Ethyl 3-methylbutyrate & - & - & - & $1.45 \pm 0.39$ & - & - & Fruity [26] \\
\hline 10 & Ethyl hexanoate & - & $2.41 \pm 0.10 \mathrm{~b}$ & - & $2.20 \pm 0.07 \mathrm{~b}$ & $87.05 \pm 9.92 \mathrm{a}$ & - & Fruity [30] \\
\hline 11 & Etheyl octanoate & - & $15.45 \pm 2.17 \mathrm{~b}$ & - & - & $108.51 \pm 4.18 \mathrm{a}$ & - & Fruity [30] \\
\hline 13 & (E)- $\beta$-Ocimene & - & - & $5.17 \pm 0.55$ & - & - & - & Fruity [27] \\
\hline 14 & Linalool & - & - & $1.92 \pm 0.14$ & - & - & - & Fruity, Floral [30] \\
\hline 15 & Citral & - & - & $4.41 \pm 0.33$ & - & - & - & Fruity * \\
\hline 16 & Geraniol & $0.65 \pm 0.01 \mathrm{~b}$ & $0.71 \pm 0.01 \mathrm{~b}$ & $64.55 \pm 6.42 \mathrm{a}$ & - & - & - & Fruity, Floral [25] \\
\hline 17 & Isobutyric acid & $0.32 \pm 0.01 \mathrm{~d}$ & $1.21 \pm 0.07 \mathrm{c}$ & $0.45 \pm 0.01 \mathrm{~d}$ & $6.79 \pm 0.24 a$ & $2.17 \pm 0.19 b$ & - & Fatty [30] \\
\hline 18 & Butanoic acid & $1.00 \pm 0.02 b$ & $1.04 \pm 0.05 b$ & - & $2.75 \pm 0.06 \mathrm{a}$ & - & - & Fatty [30] \\
\hline 19 & Isovaleric acid & - & $15.54 \pm 0.93 b$ & - & $167.05 \pm 5.18 \mathrm{a}$ & - & - & Fatty [30] \\
\hline 20 & Octanoic acid & - & $0.21 \pm 0.01 b$ & - & - & $2.16 \pm 0.08 \mathrm{a}$ & - & Fatty [30] \\
\hline 21 & Decanoic acid & - & $0.08 \pm 0.01 b$ & - & - & $1.61 \pm 0.14 \mathrm{a}$ & - & Fatty [30] \\
\hline 22 & Nonanal & $0.90 \pm 0.01 \mathrm{~cd}$ & $0.92 \pm 0.04 b c$ & $0.93 \pm 0.01 b c$ & $0.95 \pm 0.01 b$ & $1.01 \pm 0.01 \mathrm{a}$ & $0.87 \pm 0.00 \mathrm{~d}$ & $\begin{array}{l}\text { Herbaceous } \\
\text { (Green) [28] }\end{array}$ \\
\hline
\end{tabular}

Values followed by different letters in a row are significantly different $(p<0.05)$ by Duncan test. *: Aroma series were classified in the laboratory according to the odor of standards, Yunnan Agricultural University, China. 


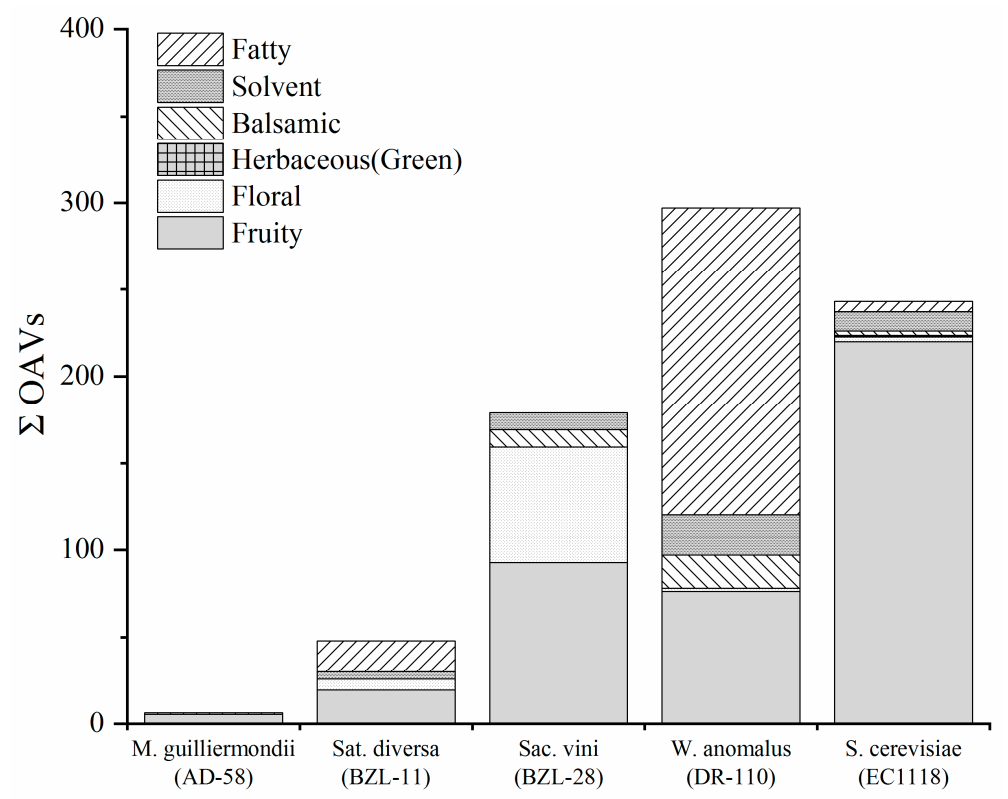

Figure 3. Sum of OAVs of different aroma series in five fermented media.

\section{Conclusions}

This study described the fermentation performances and aroma compositions of four indigenous non-Saccharomyces yeast isolates, Meyerozyma guilliermondii (AD-58), Saccharomycopsis vini (BZL-28), Saturnispora diversa (BZL-11), and Wickerhamomyces anomalus (DR-110) in the fermentation of synthetic grape juice. Sat. diversa (BZL-11) and Sac. vini (BZL-28) showed the highest and the lowest fermentation capacity, respectively, whereas M. guilliermondii (AD-58) and W. anomalus (DR-110) exhibited an intermediate fermentative capacity. These four indigenous non-Saccharomyces yeast isolates showed lower conversion rates of sugar to alcohol and higher yields of volatile acidity. W. anomalus (DR-110) had a greater ability to produce numerous esters and short-chain fatty acids, which contributed to the fruity and fatty aromas in its fermented medium. Sac. vini (BZL-28) exhibited a great capacity in the formation of monoterpenes, especially $(Z)$ - $\beta$-ocimene, $(E)$ - $\beta$-ocimene, linalool, citral, and geraniol, which can enhance the fruity (citrus-like) and floral aromas in the resultant fermented medium. Although M. guilliermondii (AD-58) and Sat. diversa (BZL-11) showed some potential in the production of 2,3-butanediol and 2-phenylethanol, respectively, the concentrations of most of the other volatiles that were produced by these two isolates were much lower than their sensory thresholds. Therefore, they may have little impact on the aroma profiles of the resultant fermented media. Our study provides more insights into the four indigenous non-Saccharomyces yeast isolates that were obtained from the Shangri-La wine region in China. These non-Saccharomyces yeast isolates may play an important role in shaping the regional characteristics of the wines that are produced from this region. Further studies on these non-Saccharomyces yeast isolates in the fermentation of local grapes at an industrial scale will provide us with more valuable information for their application in producing wines with more regional characteristics.

Supplementary Materials: The following are available online at https:/ /www.mdpi.com/article/10 .3390/jof8020146/s1, Figure S1: The colony morphologies of four non-Saccharomyces yeast isolates on YPD (A, B, C, D) and WL (a, b, c, d) agar, Figure S2: Phylogenetic tree of four non-Saccharomyces yeast isolates based on the sequence analysis of the 26S rRNA D1/D2 region using the maximumlikelihood method. The scale bar shows 0.05, Bootstrap support values were estimated based on 1000 replicates. Figure S3: Phylogenetic tree of four non-Saccharomyces yeast isolates based on the sequence analysis of the $5.8 \mathrm{~S}$ rRNA ITS region using the maximum-likelihood method. The scale bar shows 0.05, Bootstrap support values were estimated based on 1000 replicates. Table S1: Detailed information of 26S rRNA D1/D2 region and 5.8S rRNA ITS region of four non-Saccharomyces yeast 
isolates, Table S2: Identification methods, quantitative standards and calibration curves of volatile aroma compounds.

Author Contributions: Conceptualization, Y.Z. (Yifan Zhu), S.Z., F.D., R.M., S.L. and L.L.; Investigation, Y.Z. (Yue Zhao) and Q.S.; Methodology, Y.Z. (Yue Zhao) and Q.S.; Resources, Y.Z. (Yue Zhao) and Q.S.; Software, Y.Z. (Yue Zhao) and Q.S.; Writing-original draft preparation, Y.Z. (Yue Zhao) and Q.S.; Writing—review \& editing: Y.Z. (Yue Zhao), Q.S., Y.Z. (Yifan Zhu) and B.T.; Supervision: Y.Z. (Yifan Zhu). All authors have read and agreed to the published version of the manuscript.

Funding: This work was supported by the Free Exploration Project for Academicians of Yunnan Science and Technology Department (2018HA009) and the Scientific Research Fund Project of Yunnan Education Department (2020J0243).

Institutional Review Board Statement: Not applicable.

Informed Consent Statement: Not applicable.

Data Availability Statement: All data analyzed or generated during this study are available within the manuscript and can be requested from the corresponding author.

Conflicts of Interest: The authors declare no conflict of interest.

\section{References}

1. Fugelsang, K.C.; Edwards, C.G. Grape and wine microorganisms. In Wine Microbiology, 2nd ed.; Springer: New York, NY, USA, 2007; pp. 3-61.

2. Padilla, B.; Gil, J.V.; Manzanares, P. Past and future of non-Saccharomyces yeasts: From spoilage microorganisms to biotechnological tools for improving wine aroma complexity. Front. Microbiol. 2016, 7, 411. [CrossRef] [PubMed]

3. Canonico, L.; Comitini, F.; Oro, L.; Ciani, M. Sequential fermentation with selected immobilized non-Saccharomyces yeast for reduction of ethanol content in wine. Front. Microbiol. 2016, 7, 278. [CrossRef] [PubMed]

4. Gobbi, M.; De Vero, L.; Solieri, L.; Comitini, F.; Oro, L.; Giudici, P.; Ciani, M. Fermentative aptitude of non-Saccharomyces wine yeast for reduction in the ethanol content in wine. Eur. Food Res. Technol. 2014, 239, 41-48. [CrossRef]

5. del Fresno, J.M.; Morata, A.; Loira, I.; Bañuelos, M.A.; Escott, C.; Benito, S.; Chamorro, C.G.; Suárez-Lepe, J.A. Use of nonSaccharomyces in single-culture, mixed and sequential fermentation to improve red wine quality. Eur. Food Res. Technol. 2017, 243, 2175-2185. [CrossRef]

6. del Mónaco, S.M.; Barda, N.; Rubio, N.C.; Caballero, A. Selection and characterization of a Patagonian Pichia kudriavzevii for wine deacidification. J. Appl. Microbiol. 2014, 117, 451-464. [CrossRef]

7. Gobbi, M.; Comitini, F.; Domizio, P.; Romani, C.; Lencioni, L.; Mannazzu, I.; Ciani, M. Lachancea thermotolerans and Saccharomyces cerevisiae in simultaneous and sequential co-fermentation: A strategy to enhance acidity and improve the overall quality of wine. Food Microbiol. 2013, 33, 271-281. [CrossRef]

8. Merín, M.G.; de Ambrosini, V.I.M. Highly cold-active pectinases under wine-like conditions from non-Saccharomyces yeasts for enzymatic production during winemaking. Lett. Appl. Microbiol. 2015, 60, 467-474. [CrossRef]

9. Escribano, R.; González-Arenzana, L.; Portu, J.; Garijo, P.; López-Alfaro, I.; López, R.; Santamaría, P.; Gutiérrez, A.R. Wine aromatic compound production and fermentative behaviour within different non-Saccharomyces species and clones. J. Appl. Microbiol. 2018, 124, 1521-1531. [CrossRef]

10. Domizio, P.; Romani, C.; Lencioni, L.; Comitini, F.; Ciani, M.; Mannazzu, I.; Ciani, M. Outlining a future for non-Saccharomyces yeasts: Selection of putative spoilage wine strains to be used in association with Saccharomyces cerevisiae for grape juice fermentation. Int. J. Food Microbiol. 2011, 147, 170-180. [CrossRef]

11. Larroque, M.N.; Carrau, F.; Faria, L.; Boido, E.; Medina, K. Effect of Saccharomyces and non-Saccharomyces native yeasts on beer aroma compounds. Int. J. Food Microbiol. 2021, 312, 108373. [CrossRef]

12. Sadineni, V.; Kondapalli, N.; Obulam, V.S.R. Effect of co-fermentation with Saccharomyces cerevisiae and Torulaspora delbrueckii or Metschnikowia pulcherrima on the aroma and sensory properties of mango wine. Ann. Microbiol. 2012, 62, 1353-1360. [CrossRef]

13. Wei, J.P.; Zhang, Y.X.; Wang, Y.W.; Ju, H.M.; Niu, C.; Song, Z.H.; Yuan, Y.H.; Yue, T.L. Assessment of chemical composition and sensorial properties of ciders fermented with different non-Saccharomyces yeasts in pure and mixed fermentations. Int. J. Food Microbiol. 2019, 318, 108471. [CrossRef]

14. Hu, K.; Qin, Y.; Tao, Y.S.; Zhu, X.L.; Ullah, N. Potential of glycosidase from non-Saccharomyces isolates for enhancement of wine aroma. J. Food Sci. 2016, 81, 935-943. [CrossRef] [PubMed]

15. Mateo, J.J.; Peris, L.; Ibañez, C.; Maicas, S. Characterization of glycolytic activities from non-Saccharomyces yeasts isolated from Bobal musts. J. Ind. Microbiol. Biotechnol. 2011, 38, 347-354. [CrossRef] [PubMed]

16. Palmeri, R.; Spagna, G. $\beta$-Glucosidase in cellular and acellular form for winemaking application. Enzym. Microb. Technol. 2007, 40, 382-389. [CrossRef] 
17. Fernández-González, M.; Stefano, R.D.; Briones, A. Hydrolysis and transformation of terpene glycosides from muscat must by different yeast species. Food Microbiol. 2003, 20, 35-41. [CrossRef]

18. Hu, K.; Zhu, X.L.; Mu, H.; Ma, Y.; Ullah, N.; Tao, Y.S. A novel extracellular glycosidase activity from Rhodotorula mucilaginosa: Its application potential in wine aroma enhancement. Lett. Appl. Microbiol. 2016, 62, 169-176. [CrossRef]

19. Barata, A.; Malfeito-Ferreira, M.; Loureiro, V. The microbial ecology of wine grape berries. Int. J. Food Microbiol. 2012, 153, 243-259. [CrossRef]

20. Morgan, H.H.; du Toit, M.; Setati, M.E. The grapevine and wine microbiome: Insights from high-throughput amplicon sequencing Front. Microbiol. 2017, 8, 820. [CrossRef]

21. Zhao, Y.; Sun, Q.Y.; Zhu, S.S.; Du, F.; Mao, R.Z.; Liu, L.J.; Tian, B.; Zhu, Y.F. Biodiversity of non-Saccharomyces yeasts associated with spontaneous fermentation of Cabernet Sauvignon wines from Shangri-La wine region, China. Sci. Rep. 2021, 11, 5150. [CrossRef]

22. Zhang, M.X.; Pan, Q.H.; Yan, G.L.; Duan, C.Q. Using headspace solid phase micro-extraction for analysis of aromatic compounds during alcoholic fermentation of red wine. Food Chem. 2011, 125, 743-749. [CrossRef]

23. Culleré, L.; Escudero, A.; Cacho, J.; Ferreira, V. Gas chromatography-olfactometry and chemical quantitative study of the aroma of six premium quality Spanish aged red wines. J. Agric. Food Chem. 2004, 52, 1653-1660. [CrossRef] [PubMed]

24. Tao, Y.S.; Zhang, L. Intensity prediction of typical aroma characters of cabernet sauvignon wine in Changli County (China). LWT-Food Sci. Technol. 2010, 43, 1550-1556. [CrossRef]

25. Souid, I.; Hassene, Z.; Palomo, E.S.; Perez-Coello, M.S.; Ghorbel, A. Varietal aroma compounds of Vitis vinifera cv. Khamri grown in Tunisia. J. Food Qual. 2007, 30, 718-730. [CrossRef]

26. Wang, X.C.; Li, A.H.; Dizy, M.; Ullah, N.; Sun, W.X.; Tao, Y.S. Evaluation of aroma enhancement for "Ecolly" dry white wines by mixed inoculation of selected Rhodotorula mucilaginosa and Saccharomyces cerevisiae. Food Chem. 2017, 228, 550-559. [CrossRef] [PubMed]

27. de Sousa Galvão, M.; Narain, N.; dos Santos, M.S.P.; Nunes, M.L. Volatile compounds and descriptive odor attributes in umbu (Spondias tuberosa) fruits during maturation. Food Res. Int. 2011, 44, 1919-1926. [CrossRef]

28. Jiang, B.; Zhang, Z.W. Volatile compounds of young wines from cabernet sauvignon, cabernet gernischet and chardonnay varieties grown in the loess plateau region of China. Molecules 2010, 15, 9184-9196. [CrossRef]

29. Peinado, R.A.; Moreno, J.; Bueno, J.E.; Moreno, J.A.; Mauricio, J.C. Comparative study of aromatic compounds in two young white wines subjected to pre-fermentative cryomaceration. Food Chem. 2004, 84, 585-590. [CrossRef]

30. Peinado, R.A.; Mauricio, J.C.; Moreno, J. Aromatic series in sherry wines with gluconic acid subjected to different biological aging conditions by Saccharomyces cerevisiae var. capensis. Food Chem. 2006, 94, 232-239. [CrossRef]

31. Sadoudi, M.; Tourdot-Maréchal, R.; Rousseaux, S.; Steyer, D.; Gallardo-Chacon, J.J.; Ballester, J.; Vichi, S.; Guérin-Schneider, R.; Caixach, J.; Alexandrea, H. Yeast-yeast interactions revealed by aromatic profile analysis of Sauvignon Blanc wine fermented by single or co-culture of non-Saccharomyces and Saccharomyces yeasts. Food Microbiol. 2012, 32, 243-253. [CrossRef]

32. Sun, S.Y.; Gong, H.S.; Jiang, X.M.; Zhao, Y.P. Selected non-Saccharomyces wine yeasts in controlled multistarter fermentations with Saccharomyces cerevisiae on alcoholic fermentation behaviour and wine aroma of cherry wines. Food Microbiol. 2014, 44, 15-23. [CrossRef] [PubMed]

33. Mendoza, L.M.; Vega-Lopez, G.A.; de Ullivarri, M.F.; Raya, R.R. Population and oenological characteristics of non-Saccharomyces yeasts associated with grapes of Northwestern Argentina. Arch. Microbiol. 2019, 201, 235-244. [CrossRef] [PubMed]

34. Ciani, M.; Ferraro, L. Role of oxygen on acetic acid production by Brettanomyces/Dekkera in winemaking. J. Sci. Food Agric. 1997, 75, 489-495. [CrossRef]

35. Swiegers, J.H.; Pretorius, I.S. Yeast modulation of wine flavor. Adv. Appl. Microbiol. 2005, 57, 131-175. [PubMed]

36. Romano, P.; Brandolini, V.; Ansaloni, C.; Menziani, E. The production of 2,3-butanediol as a differentiating character in wine yeasts. World J. Microbiol. Biotechnol. 1998, 14, 649-653. [CrossRef]

37. Sumby, K.M.; Grbin, P.R.; Jiranek, V. Microbial modulation of aromatic esters in wine: Current knowledge and future prospects. Food Chem. 2010, 121, 1-16. [CrossRef]

38. Ye, M.Q.; Yue, T.L.; Yuan, Y.H. Effects of sequential mixed cultures of Wickerhamomyces anomalus and Saccharomyces cerevisiae on apple cider fermentation. FEMS Yeast Res. 2014, 14, 873-882.

39. Synos, K.; Reynolds, A.G.; Bowen, A.J. Effect of yeast strain on aroma compounds in Cabernet franc icewines. LWT-Food Sci. Technol. 2015, 64, 227-235. [CrossRef]

40. Carrau, F.M.; Medina, K.; Boido, E.; Farina, L.; Gaggero, C.; Dellacassa, E.; Versini, G.; Henschke, P.A. De novo synthesis of monoterpenes by Saccharomyces cerevisiae wine yeasts. FEMS Microbiol. Lett. 2005, 243, 107-115. [CrossRef]

41. Hock, R.; Benda, I.; Schreier, P. Formation of terpenes by yeasts during alcoholic fermentation. Z. Für Lebensm.-Unters. Und-Forsch. 1984, 179, 450-452. [CrossRef]

42. Wu, Q.; Zhu, W.A.; Wang, W.; Xu, Y. Effect of yeast species on the terpenoids profile of Chinese light-style liquor. Food Chem. 2015, 168, 390-395. [CrossRef] [PubMed]

43. Isaacs, C.E.; Litov, R.E.; Thormar, H. Antimicrobial activity of lipids added to human milk, infant formula, and bovine milk. J. Nutr. Biochem. 1995, 6, 362-366. [CrossRef]

44. Ogbolu, D.O.; Oni, A.A.; Daini, O.A.; Oloko, A.P. In vitro antimicrobial properties of coconut oil on Candida Species in Ibadan, Nigeria. J. Med. Food 2007, 10, 384-387. [CrossRef] [PubMed] 
45. Parfene, G.; Horincar, V.; Tyagi, A.K.; Malik, A.; Bahrim, G. Production of medium chain saturated fatty acids with enhanced antimicrobial activity from crude coconut fat by solid state cultivation of Yarrowia lipolytica. Food Chem. 2013, 136, 1345-1349. [CrossRef] [PubMed]

46. Guth, H. Quantitation and sensory studies of character impact odorants of different white wine varieties. J. Agric. Food Chem. 1997, 45, 3027-3032. [CrossRef]

47. Ferreira, V.; López, R.; Cacho, J.F. Quantitative determination of the odorants of young red wines from different grape varieties. J. Sci. Food Agric. 2000, 80, 1659-1667. [CrossRef]

48. Tat, L.; Comuzzo, P.; Battistutta, F.; Zironi, R. Sweet-like off-flavor in Aglianico del vulture wine: Ethyl phenylacetate as the mainly involved compound. J. Agric. Food Chem. 2007, 55, 5205-5212. [CrossRef] [PubMed]

49. Tamura, H.; Boonbumrung, S.; Yoshizawa, T.; Varanyanond, W. The volatile constituents in the peel and pulp of a green Thai mango, Khieo sawoei cultivar (Mangifera indica L.). Food Sci. Technol. Res. 2001, 7, 72-77. [CrossRef]

50. Ahmed, E.M.; Dennison, R.A.; Dougherty, R.H.; Shaw, P.E. Flavor and odor thresholds in water of selected orange juice components. J. Agric. Food Chem. 1978, 26, 187-191. [CrossRef]

51. Ferreira, V.; Ardanuy, M.; López, R.; Cacho, J.F. Relationship between flavor dilution values and odor unit values in hydroalcoholic solutions: Role of volatility and a practical rule for its estimation. J. Agric. Food Chem. 1998, 46, 4341-4346. [CrossRef] 